Review began 12/22/2021 Review ended 01/02/2022 Published 01/07/2022

\section{(๑) Copyright 2022}

Lehrer et al. This is an open access article distributed under the terms of the Creative Commons Attribution License CC-BY 4.0. which permits unrestricted use, distribution, and reproduction in any medium, provided the original author and source are credited.

\title{
A Component or Multiple Components of Bleeding Gums May Ameliorate Both Glaucoma and Alzheimer's Disease
}

\author{
Steven Lehrer ${ }^{1}$, Peter H. Rheinstein ${ }^{2}$, James Schmeidler ${ }^{3}$ \\ 1. Radiation Oncology, Icahn School of Medicine at Mount Sinai, New York, USA 2. Family Medicine, Severn Health \\ Solutions, Severna Park, USA 3. Psychiatry, Icahn School of Medicine at Mount Sinai, New York, USA
}

Corresponding author: Steven Lehrer, stevenlehrer@hotmail.com

\begin{abstract}
Background: Although clinical studies have shown an increased prevalence of primary open-angle glaucoma (POAG) in patients with Alzheimer's disease (AD), a population-based epidemiologic study from Denmark found no increased risk of Alzheimer's disease in patients with glaucoma, and other studies have failed to demonstrate a link. However, a possible relationship between POAG and AD might manifest in their association with oral pathology. Dental caries, periodontal disease, stomatitis, and the related inflammatory burden increase $\mathrm{AD}$ risk, while oral pathology and the oral microbiome correlate with POAG vulnerability. To further examine the relationship, we analyzed POAG, $\mathrm{AD}$, and oral disease in the UK Biobank (UKBB) cohort.

Methods: Our analysis included all subjects with POAG and AD. POAG diagnosis was ascertained using the 10th Revision of the International Classification of Diseases (ICD-10), H40.11. AD diagnosis was ascertained using the 10th Revision of the International Classification of Diseases (ICD-10), G30. Oral cavity, ulceration, stomatitis, periodontitis, teeth, and dental problems were in UKBB data field 6149.
\end{abstract}

Results: A "yes" answer to a question about bleeding gums is associated with a greater proportional POAG reduction (24.2\%) than a "yes" answer to having none of the six listed problems (6.3\%). Similarly, bleeding gums were associated with a greater proportional $\mathrm{AD}$ reduction (46.2\% versus $16.9 \%)$. Logistic regression controlling for age and sex showed that bleeding gums (no/yes) were negatively associated with AD (odds ratio $(\mathrm{OR})=0.713,95 \%$ confidence interval $(\mathrm{CI})=0.521-0.976, \mathrm{p}=0.035)$. Age-weighted least-squares linear regression showed that the lower corneal-compensated intraocular pressure (IOP) in the left eye was associated with bleeding gums (unstandardized regression coefficient $=-0.174, \mathrm{p}<0.001$ ), controlling for type 2 diabetes and past smoking.

Conclusion: It is difficult to predict what component or components of periodontal inflammation might be ameliorating POAG and AD. Prostaglandin is a possibility. Identification of the component or components could lead to new treatments for POAG and AD. Further studies are warranted.

Categories: Neurology, Ophthalmology, Dentistry

Keywords: prostaglandins, periodontitis, alzheimer's disease, neurodegeneration, glaucoma

\section{Introduction}

Glaucoma is a collection of ocular neuropathies marked by the degeneration of retinal ganglion cells (RGCs) and their axons, which results in a distinctive optic nerve appearance and visual field abnormalities. The most prevalent type of glaucoma is primary open-angle glaucoma (POAG). Glaucoma can lead to vision impairment and eventually blindness if not treated. Currently, intraocular pressure (IOP) is the sole known therapeutic component.

The most prevalent cause of dementia in the elderly is Alzheimer's disease (AD), a neurodegenerative condition that develops over time and is defined clinically as growing cognitive and behavioral impairment. $\beta$-Amyloid plaques and neurofibrillary tangles are the pathological hallmarks of Alzheimer's disease. The epsilon 4 allele of apolipoprotein E (APOE), which has been linked to POAG [1], is a substantial genetic risk factor for late-onset AD. However, the evidence on whether APOE polymorphisms enhance the incidence of POAG is mixed [2].

Structural examinations of optic nerves from patients with AD have revealed degeneration and loss of retinal ganglion cells, such as POAG. Caspase activation and the aberrant processing of amyloid precursor protein (APP), both essential processes in Alzheimer's disease, have been demonstrated in a rat model of chronic ocular hypertension. In the same type of experimental glaucoma, $\beta$-amyloid has been linked to retinal ganglion cell (RGC) apoptosis. Therefore, POAG and AD may be part of the same age-related neurodegenerative process [3]. 
Although clinical studies have shown an increased prevalence of POAG in patients with Alzheimer's disease [2], a population-based epidemiologic study from Denmark found no increased risk of Alzheimer's disease in patients with glaucoma [4]. Other studies have also failed to demonstrate a link [5-7].

A possible relationship between POAG and AD might manifest in their association with oral pathology. Dental caries, periodontal disease, stomatitis, and the related inflammatory burden increase AD risk $[8,9]$, while oral pathology and the oral microbiome correlate with POAG vulnerability [10-13].

To further examine the relationship, we analyzed POAG, AD, and oral disease in the UK Biobank (UKBB) cohort.

\section{Materials And Methods}

The UK Biobank is a major men's and women's prospective observational study. Between 2006 and 2010, participants were recruited from 22 different centers across England, Wales, and Scotland, and they are still being followed for future health events [14]. The UKBB uses the same technique as the continuing Framingham Heart Study, with the exception that UKBB gathers postmortem samples, which Framingham does not [15].

Our UK Biobank application was approved as UKB project 57245 (SL and PHR). Our analysis included all subjects with POAG and $\mathrm{AD}$, including concomitant. POAG diagnosis was ascertained using the 10th Revision of the International Classification of Diseases (ICD-10), H40.11. AD diagnosis was ascertained using the 10th Revision of the International Classification of Diseases (ICD-10), G30. Oral and dental problems were in UKBB data field 6149. A touchscreen question was presented to all subjects: "Do you have any of the following? (You can select more than one answer).” The choices were mouth ulcers, painful gums, bleeding gums, loose teeth, toothache, dentures, or none of the above. A subject could enter up to six responses. Data were collected during a single session, and no follow-up or longitudinal data were collected.

Data processing was performed on Minerva, a Linux mainframe with Centos 7.6, at the Icahn School of Medicine at Mount Sinai. We used the UK Biobank Data Parser (ukbb parser), a python-based package that allows easy interfacing with the large UK Biobank dataset [16]. Statistical analysis (Fisher's exact test and logistic regression) was done using SPSS 25 and R.

\section{Results}

The mean age of 349,549 subjects was $56 \pm 8$ (mean \pm SD), $54 \%$ were female and $46 \%$ were male, and $95 \%$ were White British. Additional demographics are in the following tables.

Oral cavity problems in subjects versus POAG (no/yes) are in Table 1 . Variability is significant $(\mathrm{p}<0.001$, chisquare test). A "yes" answer to a question about bleeding gums is associated with a greater proportional POAG reduction (24.2\%) than a "no" answer (6.3\%). 


\section{Cureus}

\begin{tabular}{|c|c|c|c|c|c|}
\hline \multirow{2}{*}{ Mouth problems } & & POAG & POAG & Total & PR \\
\hline & & No & Yes & & \\
\hline \multirow[t]{2}{*}{ None } & Count & 289,973 & 1,815 & 291,788 & \\
\hline & \% within POAG & $60.5 \%$ & $56.7 \%$ & $60.5 \%$ & $6.3 \%$ \\
\hline \multirow[t]{2}{*}{ Mouth ulcers } & Count & 48,277 & 286 & 48,563 & \\
\hline & $\%$ within POAG & $10.1 \%$ & $8.9 \%$ & $10.5 \%$ & $15.2 \%$ \\
\hline \multirow{2}{*}{ Painful gums } & Count & 15,053 & 102 & 15,155 & \\
\hline & $\%$ within POAG & $3.1 \%$ & $3.2 \%$ & $3.1 \%$ & $-3.2 \%$ \\
\hline \multirow[t]{2}{*}{ Bleeding gums } & Count & 63,422 & 321 & 63,743 & \\
\hline & $\%$ within POAG & $13.2 \%$ & $10 \%$ & $13.2 \%$ & $24.2 \%$ \\
\hline \multirow[t]{2}{*}{ Loose teeth } & Count & 20,703 & 149 & 20,852 & \\
\hline & $\%$ within POAG & $4.3 \%$ & $4.7 \%$ & $4.3 \%$ & $-9.3 \%$ \\
\hline \multirow[t]{2}{*}{ Toothache } & Count & 19,473 & 140 & 19,613 & \\
\hline & $\%$ withın POAG & $4.1 \%$ & $4.4 \%$ & $4.1 \%$ & $-7.3 \%$ \\
\hline \multirow[t]{2}{*}{ Dentures } & Count & 80,982 & 195 & $81,7 / 7$ & \\
\hline & $\%$ within POAG & $16.9 \%$ & $24.8 \%$ & $17 \%$ & $-45.9 \%$ \\
\hline \multirow[t]{2}{*}{ Total } & Count & 47,9016 & 3,203 & 482,219 & \\
\hline & $\%$ Within PUAG & $100 \%$ & $100 \%$ & $100 \%$ & \\
\hline
\end{tabular}

TABLE 1: Oral cavity problems in subjects versus primary open-angle glaucoma (POAG) (no/yes).

Variability is significant ( $p<0.001$, chi-square test). Note that the percentage of "yes" answers with bleeding gums and POAG (10\%) was lower than the percentage of "yes" answers with bleeding gums and no POAG (13.2\%). Bleeding gums appear to be associated with an even greater proportional reduction $(P R)(10 \% / 13.2 \%=0.758 ; 1-0.758=0.242=24.2 \%)$ than "none" $(56.7 \% / 60.5 \%=0.937 ; 1-0.937=0.063=6.3 \%)$. A negative PR represents a proportional increase. In Tables 1 and 3 , the total at the bottom of the table is equal to the sum of the counts for the conditions. Since the participants could select more than one condition, the total at the bottom of a column is not a total number of participants (so that the percentage for bleeding gums would be the percentage of the participants in that column with bleeding gums) but the number of "yes" answers (so the percentage for bleeding gums would be the percentage of "yes" answers in that column with bleeding gums). In Table 2, each participant can only appear once in a column.

The cross-tabulation, bleeding gums versus POAG, is in Table 2. Of the subjects without bleeding gums, $0.60 \%$ had POAG, and $0.50 \%$ of subjects with bleeding gums had POAG $(\mathrm{p}<0.001$, two-tailed Fisher's exact test). The effect of mouth ulcers on POAG was insignificant ( $p=0.323$, two-sided Fisher's exact test). The effect of painful gums on POAG was insignificant ( $p=0.125$, two-sided Fisher's exact test). 


\section{Cureus}

\begin{tabular}{|c|c|c|c|}
\hline & No POAG & POAG & Total \\
\hline No bleeding gums & 304,672 & 1,890 & 306,562 \\
\hline$\%$ & $99.4 \%$ & $0.6 \%$ & $100 \%$ \\
\hline Bleeding gums & 63,422 & 321 & 63,743 \\
\hline$\%$ & $99.5 \%$ & $0.5 \%$ & $100 \%$ \\
\hline Iotal & 368,094 & 2,211 & 370,305 \\
\hline$\%$ & $99.4 \%$ & $0.6 \%$ & $100 \%$ \\
\hline
\end{tabular}

TABLE 2: Cross-tabulation, bleeding gums versus primary open-angle glaucoma (POAG).

Of the subjects without bleeding gums, $0.6 \%$ had POAG, and $0.5 \%$ of subjects with bleeding gums had POAG ( $p=0.001$, two-tailed Fisher's exact test.

The cross-tabulation, loose teeth versus POAG, showed that $0.6 \%$ of the subjects without loose teeth had POAG and that $0.8 \%$ of the subjects with loose teeth had POAG $(\mathrm{p}<0.001$, two-tailed Fisher's exact test). The cross-tabulation, dentures versus POAG, also showed that $0.60 \%$ of the subjects without dentures had POAG and that $1 \%$ of the subjects with dentures had POAG ( $p<0.001$, two-tailed Fisher's exact test). The effect of toothache on POAG was insignificant ( $p=0.072$, two-sided Fisher's exact test). The relationship of tooth problems to POAG has been reported previously [13].

The corneal-compensated IOP of the left eye in 67,152 subjects without bleeding gums was $16.11 \pm 4.28$ and in 12,469 subjects with bleeding gums was $15.95 \pm 4.41$ ( $\mathrm{p}<0.001$, two-tailed t-test). Age-weighted leastsquares linear regression was performed. The corneal-compensated IOP of the left eye was the dependent variable, and bleeding gums (no/yes), past smoking (no/yes), and type 2 diabetes (no/yes) were the independent variables. Bleeding gums were significantly correlated with lower IOP (unstandardized regression coefficient $B=-0.174, p<0.001$ ) and independent of the effects of type 2 diabetes (unstandardized regression coefficient $\mathrm{B}=0.413, \mathrm{p}<0.001$ ) and past smoking (unstandardized regression coefficient $\mathrm{B}=0.066, \mathrm{p}=0.037$ ).

Table 3 shows mouth problems in subjects versus AD (no/yes). Variability is significant ( $<<0.001$, chisquare test). A "yes" answer to a question about bleeding gums is associated with a greater proportional AD reduction (46.2\%) than a "no" answer (16.9\%). 


\section{Cureus}

\begin{tabular}{|c|c|c|c|c|c|}
\hline \multirow{2}{*}{ Mouth problems } & & AD & AD & Total & PR \\
\hline & & No & Yes & & \\
\hline \multirow[t]{2}{*}{ None } & Count & 291,325 & 463 & 291,788 & \\
\hline & $\%$ within $A D$ & $60.50 \%$ & $50.30 \%$ & $60.50 \%$ & $16.9 \%$ \\
\hline \multirow[t]{2}{*}{ Mouth ulcers } & Count & 48,471 & 92 & 48,563 & \\
\hline & $\%$ within $A D$ & $10.10 \%$ & $10 \%$ & $10.10 \%$ & $1 \%$ \\
\hline \multirow[t]{2}{*}{ Painful gums } & Count & 15,115 & 40 & 15,155 & \\
\hline & $\%$ within $A D$ & $3.10 \%$ & $4.30 \%$ & $3.10 \%$ & $-38.7 \%$ \\
\hline \multirow{2}{*}{ Bleeding gums } & Count & 63,678 & 65 & 63,743 & \\
\hline & $\%$ within $A D$ & $13.20 \%$ & $7.10 \%$ & $13.20 \%$ & $46.2 \%$ \\
\hline \multirow[t]{2}{*}{ Loose teeth } & Count & 20,815 & 37 & 20,852 & \\
\hline & $\%$ within AD & $4.30 \%$ & $4 \%$ & $4.30 \%$ & $7 \%$ \\
\hline \multirow[t]{2}{*}{ Ioothache } & Count & 19,580 & 33 & 19,613 & \\
\hline & $\%$ withın AD & $4.10 \%$ & $3.60 \%$ & $4.20 \%$ & $14.3 \%$ \\
\hline \multirow[t]{2}{*}{ Dentures } & Count & 81,402 & 315 & $81, \pi 17$ & \\
\hline & $\%$ Witnin AD & $10.90 \%$ & $34.20 \%$ & $1 \% \%$ & $-101.2 \%$ \\
\hline Iotal & Count & 481,299 & 920 & 482,219 & \\
\hline
\end{tabular}

\section{TABLE 3: Mouth problems in subjects versus Alzheimer's disease (no/yes).}

Variability is significant $(p<0.001$, chi-square test). Note that the percentage of "yes" answers with bleeding gums and AD $(7.1 \%)$ was lower than the percentage of "yes" answers with bleeding gums and no AD (13.2\%). Bleeding gums appear to be associated with an even greater AD proportional reduction (PR) (46.2\%) than "none" (16.9\%). Dentures are associated with a $101.2 \%$ proportional increase of AD.

The cross-tabulation, bleeding gums versus $\mathrm{AD}$, is in Table 4 . Of the subjects without bleeding gums, $0.20 \%$ had $\mathrm{AD}$, and $0.10 \%$ of the subjects with bleeding gums had $\mathrm{AD}(\mathrm{p}<0.001$, two-tailed Fisher's exact test). The cross-tabulation, dentures versus $\mathrm{AD}$, also showed that $0.2 \%$ of the subjects without dentures had $\mathrm{AD}$ and that $0.4 \%$ of subjects with dentures had $\mathrm{AD}(\mathrm{p}<0.001$, two-tailed Fisher's exact test). Subjects with dentures have a higher risk of $\mathrm{AD}[17]$. The effect of mouth ulcers on $\mathrm{AD}$ was insignificant $(\mathrm{p}=0.115$, twosided Fisher's exact test). The effect of painful gums on AD was insignificant $(p=0.096$, two-sided Fisher's exact test). The effect of loose teeth on $\mathrm{AD}$ was insignificant $(\mathrm{p}=0.739$, two-sided Fisher's exact test). The effect of toothache on $\mathrm{AD}$ was insignificant ( $\mathrm{p}=0.815$, two-sided Fisher's exact test).

\begin{tabular}{|c|c|c|c|}
\hline Bleeding gums & No $A D$ & $A D$ & Total \\
\hline No & 306,094 & 468 & 306,562 \\
\hline$\%$ & $99.8 \%$ & $0.2 \%$ & $100 \%$ \\
\hline Yes & 63,678 & 65 & 63,743 \\
\hline$\%$ & $99.9 \%$ & $0.1 \%$ & $100 \%$ \\
\hline Total & 369,772 & 533 & 370,305 \\
\hline$\%$ & $99.9 \%$ & $0.1 \%$ & $100 \%$ \\
\hline
\end{tabular}

TABLE 4: Cross-tabulation, bleeding gums versus Alzheimer's disease (AD).

Of the subjects without bleeding gums, $0.20 \%$ had $A D$, and $0.10 \%$ of the subjects with bleeding gums had $A D$ ( $p=0.002$, two-tailed Fisher's exact test). 


\section{Cureus}

Logistic regression and 95\% confidence interval (CI) lower bound (LB) and upper bound (UB) of AD (no/yes) (dependent variable) and bleeding gums (no/yes), age, and sex (independent variables) are shown in Table 5. Bleeding gums were associated with $\mathrm{AD}$, with an OR of 0.713 (95\% CI = 0.521-0.976). Every year of age was associated with $\mathrm{AD}$, with an OR of $1.210(95 \% \mathrm{CI}=1.189-1.232)$. Male sex was associated with $\mathrm{AD}$, with an OR of $1.274(95 \% \mathrm{CI}=1.070-1.517)$. A previous study showed that sex was associated with the risk of dementia in the UK Biobank cohort, and the risk was lower in women than in men [18].

\begin{tabular}{|c|c|c|c|c|}
\hline & $95 \%$ LB & OR & $95 \%$ UB & $p$ value \\
\hline Bleeding gums & 0.521 & 0.713 & 0.976 & 0.035 \\
\hline Age & 1.189 & 1.210 & 1.232 & $<0.001$ \\
\hline Sex & 1.070 & 1.274 & 1.517 & 0.007 \\
\hline
\end{tabular}

TABLE 5: Logistic regression and $95 \%$ confidence interval lower bound (LB) and upper bound (UB) of Alzheimer's disease (no/yes) (dependent variable) and bleeding gums (no/yes), age, and sex (independent variables).

Bleeding gums were associated with $A D$, with an OR of 0.713 . Every year of age was associated with $A D$, with an OR of 1.210 . Male sex was associated with $A D$, with an $O R$ of 1.274 .

There was no direct relationship between POAG and $\mathrm{AD}(\mathrm{p}=0.155$, two-tailed Fisher's exact test). Other studies have reported the same lack of relationship, as noted above [4-7].

\section{Discussion}

A "yes" answer to a question about bleeding gums is associated with a greater proportional POAG reduction (24.2\%) than a "no" answer (6.3\%). The corneal-compensated left eye IOP difference in subjects with versus without bleeding gums was statistically significant, but the effect size was quite small. While clinically insignificant, the small effect size may indicate that bleeding gums are elaborating only a small amount of the substance or substances favorably affecting POAG and AD. If these substances could be identified and larger amounts administered, the effect size could be clinically significant.

The protective effect of bleeding gums against POAG and AD is probably not due to bacteria. The major periodontal pathogens Porphyromonas gingivalis, a keystone pathobiont in periodontitis, and Bacteroides forsythus and their bacterial components have been found in the brains of patients with $\mathrm{AD}$ and seem to provoke the inflammation that is a feature of $\mathrm{AD}$ [9]. There is growing interest in the role of the gingipains produced by Porphyromonas gingivalis on the enhancement of amyloid production and possible tangling of Tau proteins in Alzheimer's disease [19,20].

POAG pathophysiology is influenced by the oral microbiome. Experiments in animal models suggest that higher bacterial loads can cause neurodegeneration by activating microglia in the retina and optic nerve, mediated by toll-like receptor 4 (TLR4) signaling and complement overexpression [10].

Cytokines, such as interleukin-1 and tumor necrosis factor, and chemokines are produced during periodontal inflammation [21]. However, these substances raise IOP rather than lower it [22], and the production of TNF- $\alpha$ during periodontitis blocks insulin receptors and may contribute to an adverse effect on the control of type 2 diabetes [23].

Prostaglandins are a key component of periodontitis and stimulate bone destruction by activating matrix metalloproteinases [24]. However, prostaglandins reduce IOP, and prostaglandin analogs are available for the topical treatment of POAG [25]. Prostaglandin E2 may protect against advanced AD [26], although prostaglandins can act as neurotoxins and may be a cause of $\mathrm{AD}[27,28]$.

A limitation in our analysis includes having different variables in Table 1 versus Table 2 and Table 3 versus Table 4. The retrospective analysis of UK Biobank data lends itself to this arrangement. Moreover, the reduced significance in Table 5 for bleeding gums compared with Table 3 and Table 4 suggests the significant contribution of the Table 5 covariates. The retrospective UKBB data are valuable for hypothesis generation, but a prospective study is needed.

Having none of the listed mouth conditions is associated with a lower incidence of POAG; in other words, mouth conditions, in general, predispose to POAG. Mouth ulcers are associated with a lower incidence of POAG, suggesting that mouth ulcers may elaborate the same POAG/AD protective substance or substances as 
bleeding gums. Alternately, the lower incidence of POAG in subjects with bleeding gums may result from some of these individuals ingesting something such as aspirin, which is known to cause bleeding gums [29] and is sometimes posited as a treatment for glaucoma [30].

\section{Conclusions}

It is difficult to predict what component or components of bleeding gums or periodontal inflammation might be ameliorating POAG and AD, although prostaglandins are prime candidates. Conclusive identification of the component or components could lead to new treatments for POAG and AD. Prostaglandins are already known to be beneficial for POAG, but their effect on AD is not well established. New treatments for AD are sorely needed, and prostaglandins might be one. Further studies are warranted.

\section{Additional Information \\ Disclosures}

Human subjects: Consent was obtained or waived by all participants in this study. Animal subjects: All authors have confirmed that this study did not involve animal subjects or tissue. Conflicts of interest: In compliance with the ICMJE uniform disclosure form, all authors declare the following: Payment/services info: All authors have declared that no financial support was received from any organization for the submitted work. Financial relationships: All authors have declared that they have no financial relationships at present or within the previous three years with any organizations that might have an interest in the submitted work. Other relationships: All authors have declared that there are no other relationships or activities that could appear to have influenced the submitted work.

\section{Acknowledgements}

This work was supported in part through the computational resources and staff expertise provided by Scientific Computing at the Icahn School of Medicine at Mount Sinai. Research reported in this paper was also supported by the Office of Research Infrastructure of the National Institutes of Health under award numbers S10OD018522 and S10OD026880. The content is solely the responsibility of the authors and does not necessarily represent the official views of the National Institutes of Health.

\section{References}

1. Margeta MA, Letcher SM, Igo RP Jr, et al.: Association of APOE with primary open-angle glaucoma suggests a protective effect for APOE $\varepsilon 4$. Invest Ophthalmol Vis Sci. 2020, 61:3. 10.1167/iovs.61.8.3

2. Tamura H, Kawakami H, Kanamoto T, et al.: High frequency of open-angle glaucoma in Japanese patients with Alzheimer's disease. J Neurol Sci. 2006, 246:79-83. 10.1016/j.jns.2006.02.009

3. Mancino R, Martucci A, Cesareo M, Giannini C, Corasaniti MT, Bagetta G, Nucci C: Glaucoma and Alzheimer disease: one age-related neurodegenerative disease of the brain. Curr Neuropharmacol. 2018, 16:971-7. 10.2174/1570159X16666171206144045

4. Kessing LV, Lopez AG, Andersen PK, Kessing SV: No increased risk of developing Alzheimer disease in patients with glaucoma. J Glaucoma. 2007, 16:47-51. 10.1097/IJG.0b013e31802b3527

5. Ou Y, Grossman DS, Lee PP, Sloan FA: Glaucoma, Alzheimer disease and other dementia: a longitudinal analysis. Ophthalmic Epidemiol. 2012, 19:285-92. 10.3109/09286586.2011.649228

6. Bach-Holm D, Kessing SV, Mogensen U, Forman JL, Andersen PK, Kessing LV: Normal tension glaucoma and Alzheimer disease: comorbidity?. Acta Ophthalmol. 2012, 90:683-5. 10.1111/j.1755-3768.2011.02125.x

7. Shang X, Zhu Z, Huang Y, et al.: Associations of ophthalmic and systemic conditions with incident dementia in the UK Biobank. Br J Ophthalmol. 2021, 10.1136/bjophthalmol-2021-319508

8. Tiisanoja A, Syrjälä AM, Tertsonen M, et al.: Oral diseases and inflammatory burden and Alzheimer's disease among subjects aged 75 years or older. Spec Care Dentist. 2019, 39:158-65. 10.1111/scd.12357

9. Poole S, Singhrao SK, Kesavalu L, Curtis MA, Crean S: Determining the presence of periodontopathic virulence factors in short-term postmortem Alzheimer's disease brain tissue. J Alzheimers Dis. 2013, 36:66577. 10.3233/JAD-121918

10. Astafurov K, Elhawy E, Ren L, et al.: Oral microbiome link to neurodegeneration in glaucoma . PLoS One. 2014, 9:e104416. 10.1371/journal.pone.0104416

11. Polla D, Astafurov K, Hawy E, Hyman L, Hou W, Danias J: A pilot study to evaluate the oral microbiome and dental health in primary open-angle glaucoma. J Glaucoma. 2017, 26:320-7. 10.1097/IJG.0000000000000465

12. Nayyar A, Gindina S, Barron A, Hu Y, Danias J: Do epigenetic changes caused by commensal microbiota contribute to development of ocular disease? A review of evidence. Hum Genomics. 2020, 14:11. 10.1186/s40246-020-00257-5

13. Pasquale LR, Hyman L, Wiggs JL, et al.: Prospective study of oral health and risk of primary open-angle glaucoma in men: data from the health professionals follow-up study. Ophthalmology. 2016, 123:2318-27. 10.1016/j.ophtha.2016.07.014

14. Arthur RS, Wang T, Xue X, Kamensky V, Rohan TE: Genetic factors, adherence to healthy lifestyle behavior, and risk of invasive breast cancer among women in the UK Biobank. J Natl Cancer Inst. 2020, 112:893-901. 10.1093/jnci/djz241

15. Mahmood SS, Levy D, Vasan RS, Wang TJ: The Framingham Heart Study and the epidemiology of cardiovascular disease: a historical perspective. Lancet. 2014, 383:999-1008. 10.1016/S0140-6736(13)617523

16. Lawrence KE, Nabulsi L, Santhalingam V, et al.: Age and sex effects on advanced white matter microstructure measures in 15,628 older adults: a UK Biobank study. Brain Imaging Behav. 2021, 
10.1007/s11682-021-00548-y

17. Popovac A, Čelebić A, Peršić S, Stefanova E, Milić Lemić A, Stančić I: Oral health status and nutritional habits as predictors for developing Alzheimer's disease. Med Princ Pract. 2021, 30:448-54.

$10.1159 / 000518258$

18. Gong J, Harris K, Peters SA, Woodward M: Sex differences in the association between major cardiovascular risk factors in midlife and dementia: a cohort study using data from the UK Biobank. BMC Med. 2021, 19:110. 10.1186/s12916-021-01980-z

19. Dominy SS, Lynch C, Ermini F, et al.: Porphyromonas gingivalis in Alzheimer's disease brains: evidence for disease causation and treatment with small-molecule inhibitors. Sci Adv. 2019, 5:eaau3333. 10.1126/sciadv.aau3333

20. Haditsch U, Roth T, Rodriguez L, et al.: Alzheimer's disease-like neurodegeneration in Porphyromonas gingivalis infected neurons with persistent expression of active gingipains. J Alzheimers Dis. 2020, 75:136176. 10.3233/IAD-200393

21. Graves DT: The potential role of chemokines and inflammatory cytokines in periodontal disease progression. Clin Infect Dis. 1999, 28:482-90. 10.1086/515178

22. Freedman J, Iserovich P: Pro-inflammatory cytokines in glaucomatous aqueous and encysted Molteno implant blebs and their relationship to pressure. Invest Ophthalmol Vis Sci. 2013, 54:4851-5. 10.1167/iovs.13-12274

23. Nishimura F, Murayama Y: Periodontal inflammation and insulin resistance--lessons from obesity . J Dent Res. 2001, 80:1690-4. 10.1177/00220345010800080201

24. Graves DT, Jiang Y, Genco C: Periodontal disease: bacterial virulence factors, host response and impact on systemic health. Curr Opin Infect Dis. 2000, 13:227-32. 10.1097/00001432-200006000-00005

25. Toris CB, Gabelt BT, Kaufman PL: Update on the mechanism of action of topical prostaglandins for intraocular pressure reduction. Surv Ophthalmol. 2008, 53 Suppl1:S107-20.

10.1016/i.survophthal.2008.08.010

26. Combrinck M, Williams J, De Berardinis MA, Warden D, Puopolo M, Smith AD, Minghetti L: Levels of CSF prostaglandin E2, cognitive decline, and survival in Alzheimer's disease. J Neurol Neurosurg Psychiatry. 2006, 77:85-8. 10.1136/innp. 2005.063131

27. Prasad KN, Hovland AR, La Rosa FG, Hovland PG: Prostaglandins as putative neurotoxins in Alzheimer's disease. Proc Soc Exp Biol Med. 1998, 219:120-5. 10.3181/00379727-219-44323

28. Minhas PS, Latif-Hernandez A, McReynolds MR, et al.: Restoring metabolism of myeloid cells reverses cognitive decline in ageing. Nature. 2021, 590:122-8. 10.1038/s41586-020-03160-0

29. Mauer AC, Khazanov NA, Levenkova N, et al.: Impact of sex, age, race, ethnicity and aspirin use on bleeding symptoms in healthy adults. J Thromb Haemost. 2011, 9:100-8. 10.1111/j.1538-7836.2010.04105.x

30. Attarzadeh A, Hosseini H, Nowroozizadeh S: Therapeutic potentials of aspirin in glaucomatous optic neuropathy. Med Hypotheses. 2006, 67:375-7. 10.1016/j.mehy.2006.01.033 